\title{
Anatomia foliar de Alpinia zerumbet (Pers.) Burtt \& Smith (Zingiberaceae) $)^{1}$
}

\author{
Elaine Santiago Brilhante de Albuquerque ${ }^{2,4}$ e Léa de Jesus Neves ${ }^{3}$
}

Recebido em 18/03/2003. Aceito em 22/07/2003

\begin{abstract}
RESUMO - (Anatomia foliar de Alpinia zerumbet (Pers.) Burtt \& Smith (Zingiberaceae)). Foi realizado o estudo da anatomia foliar de Alpinia zerumbet (Pers.) Burtt \& Smith, espécie da família Zingiberaceae, coletada no Horto Botânico da Quinta da Boa Vista, São Cristóvão, Rio de Janeiro, RJ. A espécie é vulgarmente conhecida como colônia, destacando-se pela beleza de suas inflorescências e pelo valor medicinal que lhe é atribuído. O presente estudo tem como objetivo fornecer dados que possam contribuir para a compreensão das características morfológicas da espécie e da taxonomia da família. Anatomicamente a folha apresenta organização dorsiventral do mesofilo, caráter não peculiar à maioria das monocotiledôneas, e pela ocorrência de células oleíferas dispersas no mesofilo e na epiderme da face abaxial. A folha é anfiestomática e apresenta hipoderme em ambas as faces.
\end{abstract}

Palavras-chaves: Alpinia zerumbet, Zingiberaceae, anatomia foliar

\begin{abstract}
Leaf anatomy of Alpinia zerumbet (Pers.) Burtt \& Smith (Zingiberaceae)). It was accomplished a study of the foliar anatomy of Alpinia zerumbet (Pers.) Burtt \& Smith, Zingiberaceae family collected at Horto Botânico of Quinta da Boa Vista, São Cristóvão, Rio de Janeiro, RJ. This species is vulgarly known as "colônia" and is distinguished by its beautiful inflorescence and medicinal value. The main objective of this research is to contribute to the understanding of the morphological characteristics of this species as well its family taxonomy. Anatomically, the leaf presents a dorsiventral organization of the mesophyll, disaccording with most monocotyledonous. Another remarkable aspect is the presence of scattered oil cells throughout the mesophyll and abaxial surface of the leaf. The leaf is amphistomatic and presents hypodermis on both sides.
\end{abstract}

Key words: Alpinia zerumbet, Zingiberaceace, leaf anatomy

\section{Introdução}

A família Zingiberaceae é a maior da ordem Zingiberales, constituída de 53 gêneros e mais de 1.200 espécies nativas de regiões tropicais, especialmente do sul e sudeste da Ásia (Cronquist 1981; Kress et al. 2002), expandindo-se através da África tropical até a América do Sul e Central (Tomlinson 1969). Suas espécies, principalmente da floresta primária, crescem em hábitats sombreados ou semi-sombreados, ricos em húmus (Dahlgren et al. 1985).

Muitas espécies da família têm valor econômico fornecendo alimentos (féculas dos rizomas), perfumes, condimentos de propriedades aromáticas, corantes, fibras e papel (Tomlinson 1969). Zingiber officinale Rosc., vulgarmente conhecido como gengibre, é utilizado para fins medicinais e como condimento (Joly 1993). No aspecto ornamental destacam-se os gêneros
Zingiber, Alpinia, Nicolaia, Hedychium e Kaempferia pela beleza da folhagem e da inflorescência (Winters 1995).

Alpinia é o maior gênero da família, com mais de 200 espécies (Cronquist 1981) e ocorre na Malásia e nas ilhas do Oceano Pacífico (Dahlgren et al. 1985).

A espécie estudada, Alpinia zerumbet (Pers.) Burtt \& Smith, muito cultivada pela beleza de suas flores (Joly 1993), é conhecida pelos nomes vulgares de colônia, paco-seroca, cuité-açu, pacová (Almeida,1993), gengibre-concha (Lorenzi \& Souza 1995), cardamomodo-mato, cardamomo-falso, cana-do-brejo, cana-domato e paco-seroso (Machado 1996).

Segundo Almeida (1993), as propriedades medicinais da espécie estão relacionadas às folhas, flores e rizomas, sendo consideradas depurativas, diuréticas, anti-histéricas, estomáquicas e vermífugas. É ainda, utilizada por lavradores da região de Ribeirão Preto (SP)

\footnotetext{
1 Parte da Dissertação de Mestrado da primeira Autora

2 Centro Universitário Augusto Motta, UNISUAM, Centro de Ciências da Saúde, Av. Paris, 72, Bonsucesso, CEP 21041-020, Rio de Janeiro, RJ, Brasil

3 Museu Nacional, Universidade Federal do Rio de Janeiro, Departamento de Botânica, Quinta da Boa Vista, São Cristóvão, CEP 20940-040, Rio de Janeiro, RJ, Brasil

4 Autor para correspondência: esbabio@uol.com.br
} 
no tratamento de reumatismo e males cardíacos (Carlini 1972).

A espécie tem sido largamente estudada em relação às suas propriedades farmacológicas. Os estudos com o chá das folhas da colônia realizados por Mendonça et al. (1991) e Laranja et al. (1992) confirmam o seu efeito hipotensor. Os estudos realizados por Fonteles \& Oliveira (1984 apud Almeida 1993) revelaram resultados significativos quanto ao efeito diurético, entretanto, os mesmos não foram obtidos por Laranja et al. (1992). Santana et al. (1966) mostraram ação antiinflamatória capaz de inibir processos edematosos. A colônia tem sido também estudada em relação às atividades antifúngicas (Lima et al. 1993) e antibacterianas, além da produção de inseticidas a partir dos óleos essenciais da flor (Morita 1992). A composição química dos óleos essenciais encontrados na folha e no rizoma da espécie foi estudada por Fujita \& Yamashita (1973) e por De Pooter et al. (1995).

O uso de óleos essenciais remonta a antigos períodos da história humana (Fahn 1979) fornecendo, ainda hoje, o material bruto para indústrias de inseticidas, antissépticos, produtos farmacêuticos, perfumes e condimentos. Segundo Wattiez \& Sternon (1942), a ação antimicrobiana dos óleos essenciais é variável para cada tipo de óleo e tipo de bactéria. De Pooter et al. (1995) e Morita (1992) estudando Alpinia speciosa, e Rao \& Nigam (1970), Curcuma zedoaria, confirmaram a atividade antimicrobiana dos óleos essenciais; enquanto Janssen \& Scheffer (1985) e Kishore et al. (1987) comprovam a atividade antifúngica dos óleos essenciais dos rizomas de Alpinia galanga e Alpinia carinata, respectivamente.

O presente trabalho objetivou o estudo da anatomia foliar de Alpinia zerumbet visando contribuir para o conhecimento da morfologia da espécie e para a taxonomia da família Zingiberaceae, tal como desenvolvido por Tomlinson (1956; 1962; 1969); Metcalfe (1963); Goldberg (1989); Hussin et al. (2000). A escolha da espécie, embora pertencente ao contingente das plantas exóticas, foi motivada por seu largo cultivo e emprego na medicina popular, assim como por suas propriedades terapêuticas já comprovadas.

\section{Material e métodos}

O material estudado foi oriundo do Horto Botânico do Museu Nacional/UFRJ, Quinta da Boa Vista, Rio de Janeiro, Albuquerque 1 (R).

As folhas foram coletadas no período de 1996 a 1998. Parte foi fixada em álcool etílico a $70^{\circ} \mathrm{GL}$
(Johansen 1940) e em FAA 70\% (Sass 1951) para ser submetida às técnicas histológicas, e parte mantida a fresco para a realização dos testes histoquímicos. Os cortes histológicos foram obtidos com auxílio do micrótomo manual, tipo Ranvier, e de congelação filtro Leitz 1213, utilizando-se folhas plenamente desenvolvidas e, ocasionalmente, folhas jovens para o acompanhamento do processo de morfogênese do tecido subepidérmico.

O estudo organográfico foi realizado com observações à vista desarmada e sob estereomicroscópio, sendo os pormenores estruturais representados com auxílio de câmara-clara. As convenções adotadas no esquema referente ao pecíolo estão de acordo com Metcalfe \& Chalk (1950). As fotomicrografias foram obtidas com o auxílio do microscópio Orthoplan, de Leitz, com equipamento fotográfico Orthomat.

A epiderme foi destacada manualmente e corada com Safranina hidroalcoólica (Strasburger 1924). Para os cálculos da densidade estomática por $\mathrm{mm}^{2} \mathrm{em}$ cada face, utilizou-se 10 folhas. Foi feita a projeção de um campo correspondente a um quadrado de $1 \mathrm{~mm}$ de lado, calculando-se a média aritmética dos estômatos em 30 campos.

Os testes histoquímicos foram feitos em secções realizadas à mão livre, de material fresco, sendo submetidas aos seguintes reagentes: Sudan III e IV (Johansen 1940), para observação de compostos de natureza lipídica; reagentes de Benedict (McLean \& Ivimey-Cook 1958) e de Fehling (Sass 1951), para identificação de glicídios redutores; lugol (Johansen 1940), para grãos de amido; solução aquosa de sulfato ferroso em formalina (Johansen 1940) e reagente de Hoepfner-Vorsatz (Reeve 1951), para evidenciação de compostos tânicos; reagente de Mayer (Costa 1982) e iodo iodeto de potássio (Dop \& Gautié 1928), para alcalóides; azul de metileno (Langeron 1949) e vermelho de rutênio (Jensen 1962), para identificação de mucilagem celulósica e péctica, respectivamente; cristais de fenol (Howarth \& Warne 1959) e ácido fluorídrico (Vogel 1981), para coloração e dissolução de sílica, respectivamente. Cristais de oxalato de cálcio foram reconhecidos pela solubilidade em ácido hidroclórico a 2\% (Howarth \& Warne 1959)

Para a identificação do conteúdo das células oleíferas, os cortes histológicos foram tratados com benzina, clorofórmio, éter (Beille 1925; Wattiez \& Sternon 1942), cloral hidratado, ácido acético e hidróxido de potássio (Beille 1925) para testar sua solubilidade; com Sudan III, Sudan III em solução de cloral hidratado, 
nitrato de prata a $1 \%$ (Wattiez \& Sternon 1942) e solução aquosa de acetato de cobre (Beille 1925; Wattiez \& Sternon 1942) para testar sua afinidade tintorial. A volatilidade do conteúdo foi testada em banho-maria (Beille 1925). Para a evidenciação de suberina na parede celular das células oleíferas, as secções das folhas foram tratadas em solução de hidróxido de potássio a $10 \%$ e cloreto de zinco iodado (Tomlinson 1956).

\section{Resultados}

Caracterização morfológica - Alpinia zerumbet é planta herbácea, perene, atingindo $2,5 \mathrm{~m}$ alt., rizomatosa, com caule aéreo curto, folhas lanceoladas em disposição dística, (Fig. 1, 2) de base aguda e ápice cuspidado, pubescentes nos bordos. As folhas são curto-pecioladas, com longa bainha aberta e lígula desenvolvida. A sobreposição das bainhas origina um pseudo-caule.
Lâmina foliar - A epiderme, em visão frontal, mostra células poligonais de paredes retas, levemente espessadas, por vezes arqueadas ordenadas em fileiras (Fig. 3, 4). Tricomas ocorrem somente nos bordos, e estômatos, do tipo paracítico, acham-se em densidade equivalente a $7,3 / \mathrm{mm}^{2}$ na face adaxial, e a $149 / \mathrm{mm}^{2}$ na abaxial. Nesta face encontram-se ainda estômatos do tipo tetracítico (Fig. 4). As células epidérmicas sobre as regiões costais têm dimensões reduzidas, paredes suberificadas e encerram corpúsculos arredondados de natureza silicosa (Fig. 3, 4).

As células epidérmicas, em secção transversal, mostram contorno retangular (Fig. 5, 6, 7) e campos de pontoação nas paredes anticlinais.

Foram identificados na epiderme gotículas de óleo e alcalóides, além de grãos de amido nas células oclusivas dos estômatos. Registraram-se ainda, na face abaxial, grande concentração de gotículas de óleo nas células
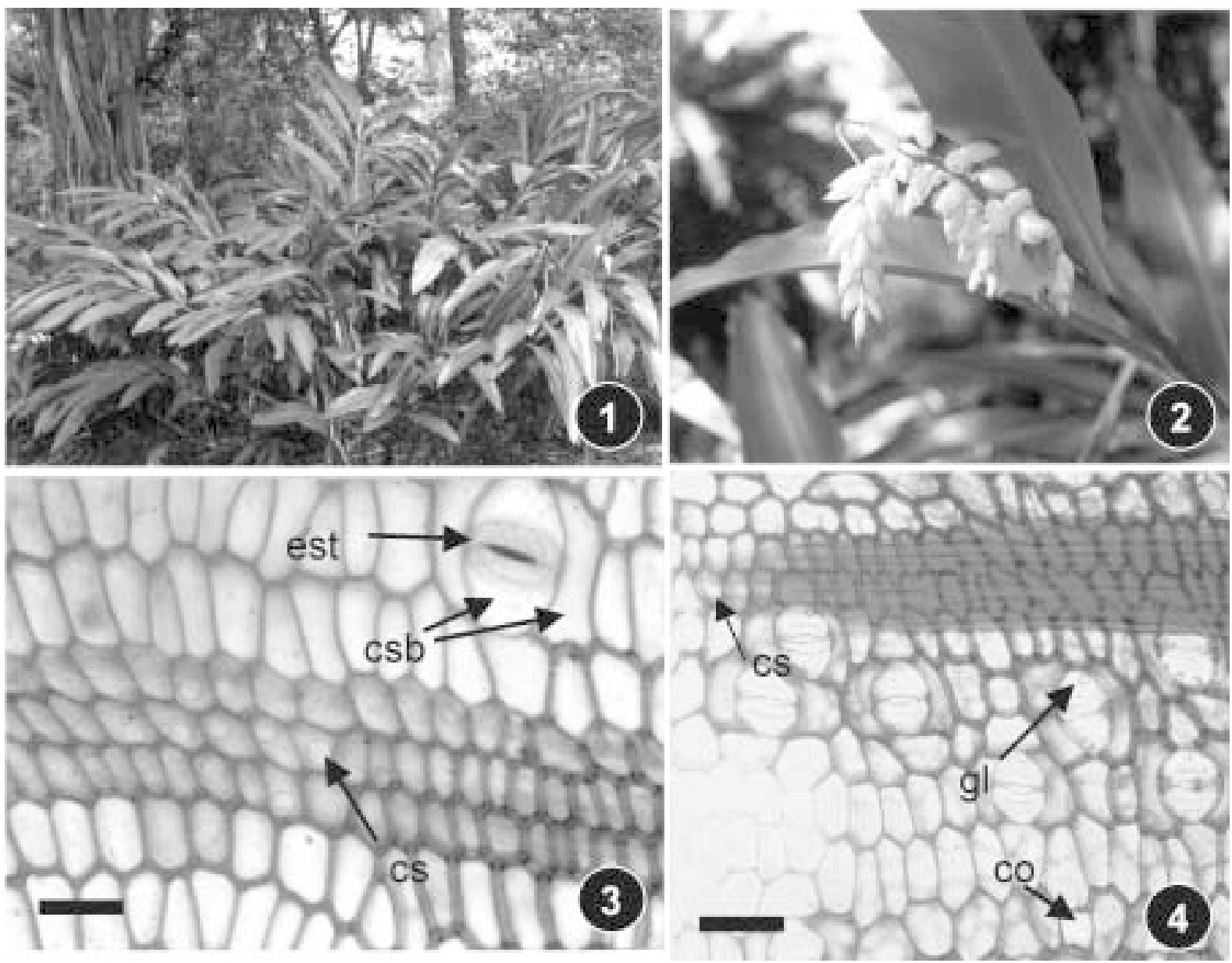

Figuras 1-4. Hábito (1-2) e vista frontal da epiderme de Alpinia zerumbet (3-4). 1. Aspecto geral do exemplar documentado no Horto Botânico do Museu Nacional. 2. Detalhe da inflorescência. 3. Face adaxial: estômato tetracítico e células sobre a nervura contendo corpúsculo silicoso $($ barra $=30 \mu \mathrm{m})$. 4 . Face abaxial: estômatos tetracíticos (barra $=44 \mu \mathrm{m})$. co - célula oleífera; cs - corpúsculo silicoso; csb - células subsidiárias; est - estômato; gl - gotícula lipídica. 
subsidiárias dos estômatos e células oleíferas (Fig. 4) que se destacam pelo formato pentagonal em secção transversal (Fig. 5).

Sob a epiderme, encontra-se de um a três estratos hipodérmicos (Fig. 5, 6, 7) constituídos de células grandes, de formato arredondado ou quadrangular, de paredes finas com numerosos campos de pontoações visíveis, principalmente nas paredes anticlinais. A hipoderme freqüentemente acha-se interrompida pela extensão da bainha fibrosa dos feixes vasculares, que se comunica com o estrato epidérmico. As células hipodérmicas reagem ao teste para identificação de mucilagem e óleo.

O mesofilo possui organização dorsiventral, formado por um estrato de parênquima paliçádico e por três ou quatro estratos de parênquima lacunoso, os quais se comunicam através de um estrato de células coletoras (Fig. 6). Por todo o mesofilo encontram-se células oleíferas (Fig. 6) e cristais prismáticos de oxalato de cálcio (Fig. 7).

Os feixes vasculares do tipo colateral acham-se envolvidos por bainha parenquimática com extensão de natureza esclerenquimática (Fig. 5, 6). As células do parênquima lacunoso que se comunicam com a bainha parenquimática do feixe dispõem-se radialmente, assemelhando-se a uma coroa (Fig. 6).

Mucilagem ocorre nas células dos parênquimas paliçádico e lacunoso, enquanto que gotículas de óleo ocorrem em todo o mesofilo, no floema e na bainha parenquimática dos feixes. O parênquima reage positivamente para os testes de amido e compostos tânicos. Açúcares redutores são encontrados no

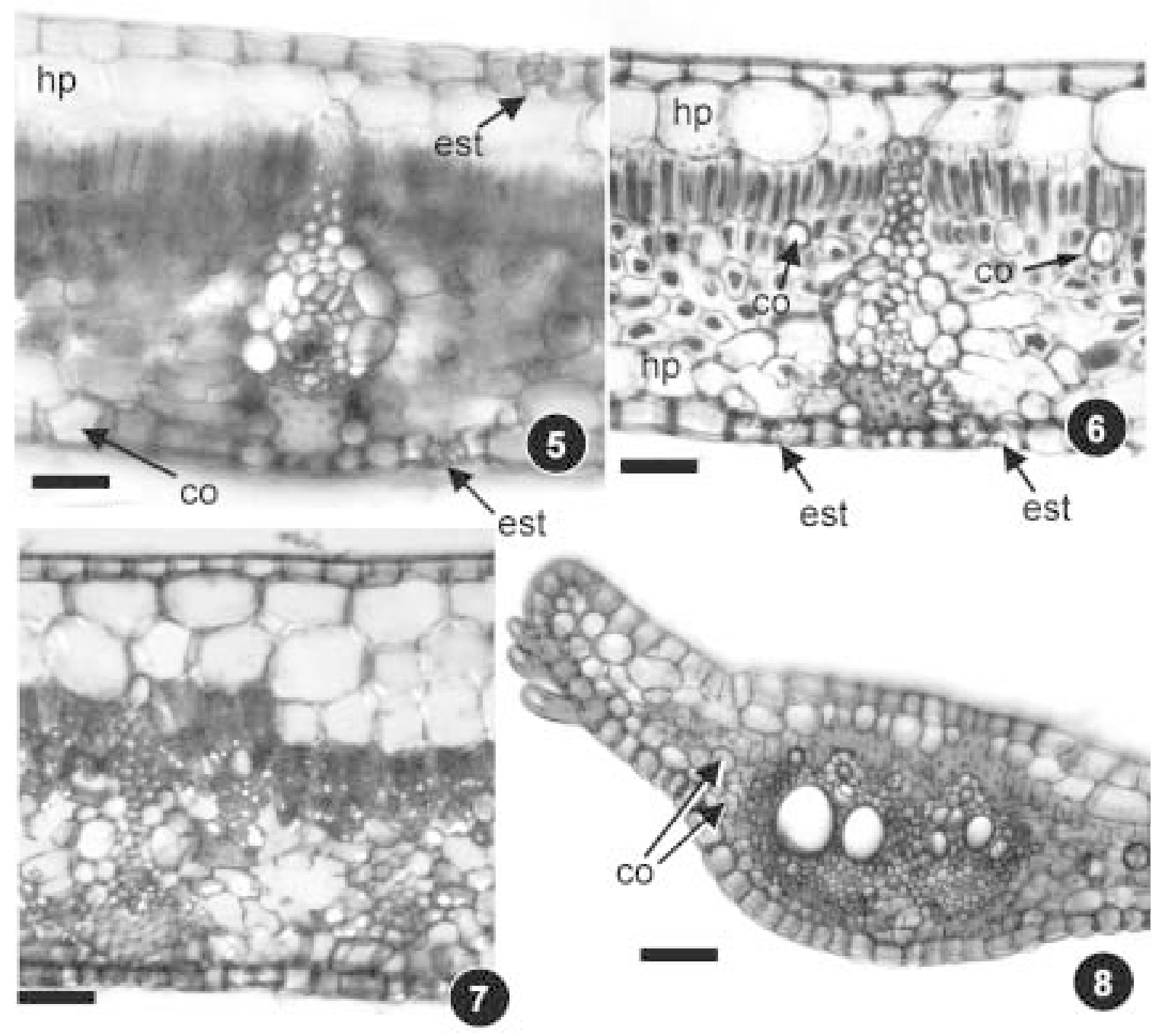

Figuras 5-8. Secções transversais da lâmina foliar de Alpinia zerumbet. 5. Notam-se estômatos em ambas as faces e célula oleífera na epiderme da face abaxial (barra $=37 \mu \mathrm{m})$. 6. Organização dorsiventral do mesofilo e células oleíferas $($ barra $=88 \mu \mathrm{m})$. 7 . Região próxima à nervura mediana, mostrando cristais no mesofilo em luz polarizada (barra $=58 \mu \mathrm{m})$. 8 . Detalhe do bordo evidenciando tricomas, feixe

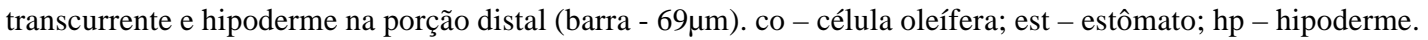


parênquima paliçádico, bem como alcalóides no floema.

O bordo do limbo, em secção transversal, mostra-se fletido para a face adaxial (Fig. 8); apresenta tricomas tectores longos com paredes espessas, que reagem positivamente ao teste de compostos tânicos. As células epidérmicas têm forma elíptica ou retangular, paredes anticlinais e periclinais espessas. Na região do bordo, as células dos parênquimas paliçádico e lacunoso são menores, e ocorrem células oleíferas (Fig. 8). As células hipodérmicas, na porção distal do bordo, mostram paredes espessadas. O tecido vascular está representado por um ou dois feixes de grande porte de caráter transcurrente (Fig. 8).
Nervura mediana - A nervura mediana, no terço médio do limbo, exibe secção transversal côncavo-convexa (Fig. 9). A epiderme da face adaxial apresenta células retangulares com numerosos cristais de sílica e impregnação de suberina, a qual se manifesta também nas paredes periclinais internas podendo, ocasionalmente, estender-se através dos estratos subepidérmicos (Fig. 10).

A epiderme da face abaxial exibe células de forma retangular a elíptica, com paredes periclinais externas arqueadas, espessadas, anisotrópicas, recobertas por uma tênue cutícula. Estão presentes estômatos com amplas câmaras subestomáticas, assim como tricomas

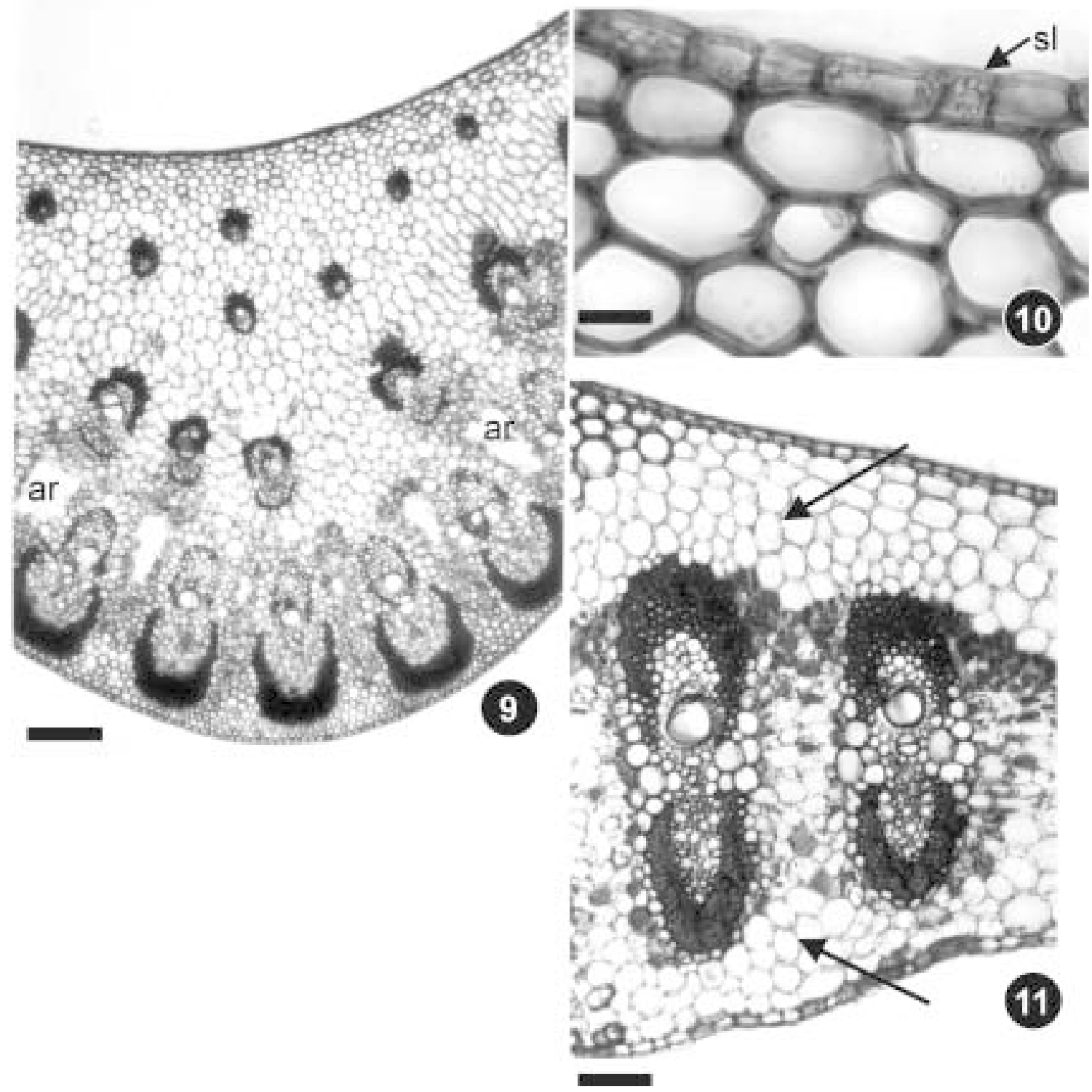

Figuras 9-11. Secções transversais da nervura mediana. 9. Aspecto geral (barra $=233 \mu \mathrm{m})$. 10. Face adaxial: cristais de sílica nas células epidérmicas $($ barra $=29 \mu \mathrm{m})$. 11. Região de contato entre a nervura e a lâmina: notam-se estratos subepidérmicos (setas) sem afinidade tintorial (barra $=100 \mu \mathrm{m})$. ar - aerênquima; $\mathrm{sl}$ - cristal de sílica. 
simples, unicelulares, curtos, posicionados, preferencialmente, na região entre a nervura e a lâmina. À semelhança das células da face adaxial, ocorrem numerosos cristais de sílica.

O limite entre os tecidos da nervura e da lâmina está marcado, em ambas as faces, pela interrupção do tecido subepidérmico suberificado e pela ocorrência de um conjunto de células com paredes espessadas, dispostas em até cinco estratos que, na face abaxial, penetram entre os feixes vasculares. Esses elementos têm fraca ou nenhuma afinidade tintorial, distinguindose facilmente dos tecidos celulósicos e lignificados (Fig. 11).

O sistema vascular da nervura dispõe-se em três níveis (Fig. 9). Feixes de pequeno porte, envolvidos por bainha esclerenquimática, estão relacionados à face adaxial (Fig. 9). Feixes de médio porte, guarnecidos por casquetes de fibras, mais volumosos em relação à porção xilemática, acham-se posicionados ao nível mediano do parênquima fundamental, enquanto os feixes mais calibrosos acham-se relacionados à face abaxial, estando também guarnecidos por casquetes de fibras, no entanto, mais desenvolvidos em relação ao floema (Fig. 9). Entre os feixes de grande porte, o parênquima fundamental mostra especialização exibindo células menores, ricas em cloroplastos e cristais prismáticos de oxalato de cálcio, delimitando grandes espaços intercelulares preenchidos por células braciformes (Fig. 9). Células oleíferas ocorrem, em baixa freqüência, próximas aos grandes espaços intercelulares.

Pecíolo - A região mediana mostra secção transversal plano-convexa, observando-se na face adaxial projeção mais ou menos acentuada dos bordos (Fig. 12). As células epidérmicas, na face adaxial, apresentam forma retangular, em secção transversal, com paredes espessadas, em maior grau as anticlinais e periclinais internas (Fig. 13). As células que revestem as porções laterais e abaxial do pecíolo podem, contudo, exibir espessamento uniforme de todas as paredes celulares (Fig. 14, 15). Nessas regiões, as células são menores que as da face adaxial (Fig. 14, 15). Células oleíferas acham-se aleatoriamente distribuídas entre os elementos epidérmicos, distinguindo-se pela forma, em geral pentagonal, e pelo adelgaçamento da parede celular (Fig. 14). Os tricomas curtos, unicelulares, com paredes espessadas ocorrem exclusivamente na região limítrofe ao bordo, enquanto os estômatos posicionam-se nas laterais e mediana do arco abaxial.

Internamente à epiderme, observa-se um tecido parenquimático que assume características próprias

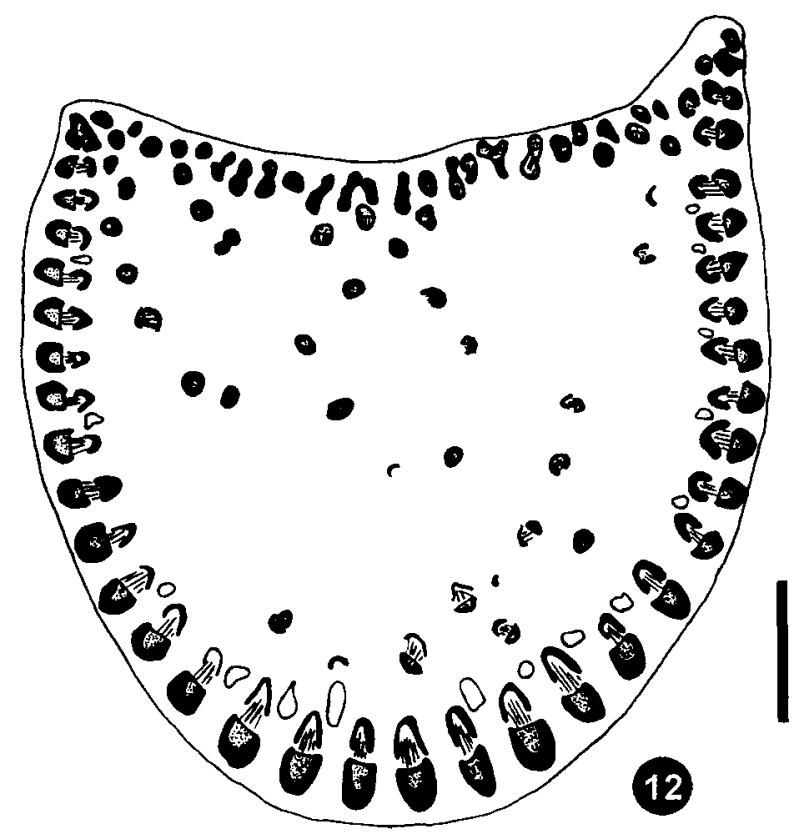

Figura 12. Diagrama do pecíolo em secção transversal, evidenciando a disposição do tecido vascular (barra $=1 \mathrm{~mm}$ ).

segundo sua posição no órgão. Os estratos adjacentes à epiderme adaxial, em número de três a quatro, exibem células de paredes moderadamente espessadas e suberificadas (Fig. 13), contrastando com os elementos subepidérmicos da área correspondente ao bordo, onde o parênquima adquire caráter colenquimático, por vezes assemelhando-se a colênquima angular (Fig. 14). Os elementos parenquimáticos adjacentes à face abaxial, dispostos em três a cinco estratos na porção mediana do arco, exibem também paredes levemente espessadas, com diferentes graus de suberificação (Fig. 15). Outra especialização do parênquima corresponde à formação de um aerênquima posicionado entre os feixes vasculares de maior calibre, e relacionados à face abaxial do pecíolo (Fig. 16). Os espaços delimitados pelas células parenquimáticas estão, em parte, ocupados por células braciformes. $\mathrm{O}$ restante da estrutura exibe parênquima fundamental com células de paredes finas, secção arredondada ou poligonal e dimensões variáveis segundo sua localização (Fig. 13-15). Assim, os elementos mais calibrosos estão localizados na porção central da secção.

Os feixes vasculares têm distribuição irregular, exceto os grandes feixes, que acompanham o arco abaxial da estrutura (Fig. 15). Os feixes são colaterais, protegidos por dois casquetes de fibras, sendo o mais desenvolvido relacionado à porção floemática (Fig. 15). $\mathrm{O}$ arco esclerenquimático que guarnece a porção xilemática, além de ter menor número de elementos, 
exibe paredes menos espessadas (Fig. 15). Relacionados à face adaxial encontram-se feixes muito reduzidos, totalmente envolvidos por um cordão de fibras, cujas paredes mostram diferentes graus de espessamento (Fig. 13). Entre os feixes vasculares, intercalam-se cordões de fibras mais ou menos desenvolvidos chegando, por vezes, a se anastomosarem com os elementos mecânicos que envolvem os feixes (Fig. 13). Ainda, por todo o parênquima, são observados pequenos feixes guarnecidos por elementos mecânicos mais desenvolvidos em relação à porção xilemática (Fig. 14).

No parênquima observam-se pequenos cristais prismáticos de oxalato de cálcio (Fig. 16). Células oleíferas acham-se predominantemente distribuídas no parênquima próximo aos feixes de grande porte (Fig. 16). Compostos taníferos foram observados na epiderme e no parênquima.

A região proximal do pecíolo distingue-se da mediana por apresentar cinco pequenos feixes vasculares envolvidos por bainha esclerenquimática, intercalados com os feixes de grande porte; e pela disposição dos casquetes de fibras dos feixes vasculares mais calibrosos, que se tocam através de suas extremidades acabando por soldarem-se formando um anel contínuo, sobretudo nos feixes vasculares posicionados nas laterais do arco.

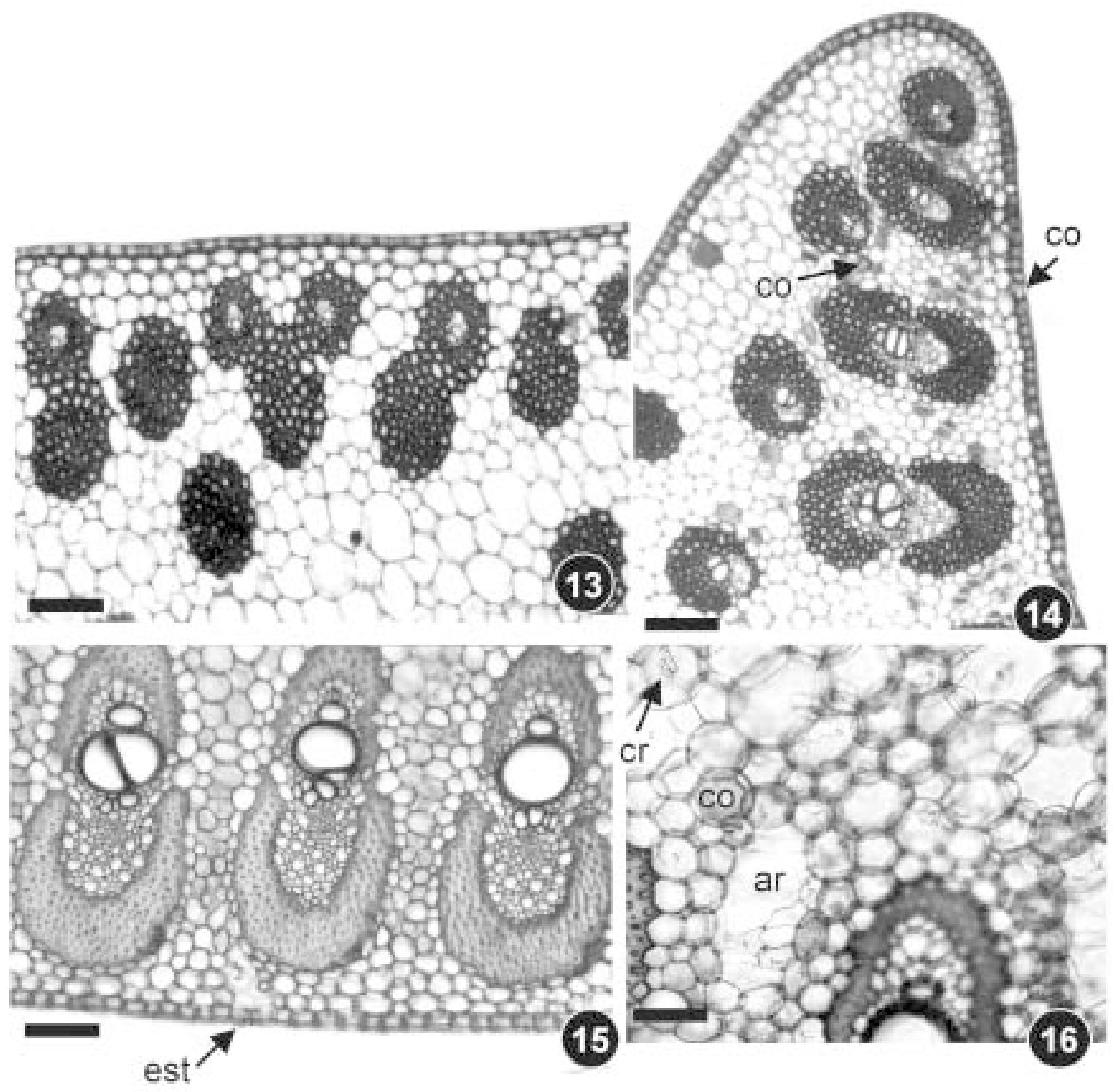

Figuras 13-16. Seções transversais do pecíolo. 13. Face adaxial: estratos subepidérmicos com paredes espessadas e feixes vasculares (barra $=100 \mu \mathrm{m}) .14$. Bordo projetado: feixes vasculares e células oleíferas (barra $=100 \mu \mathrm{m}) .15$. Face abaxial: feixes de grande porte protegidos por casquetes de fibras. $($ barra $=90 \mu \mathrm{m})$. 16. Face abaxial: presença de aerênquima, células oleíferas e cristais $($ barra $=90 \mu \mathrm{m})$. ar - aerênquima; co - célula oleífera; cr - cristais; est - estômato. 
Na região proximal da lígula, verifica-se que a epiderme é constituída por células altas em paliçada, exibindo paredes fortemente cutinizadas (Fig. 18). Os estratos subepidérmicos apresentam células com paredes espessadas (Fig. 18).

A lígula, com textura membranácea, exibe epiderme uniestratificada (Fig. 17). Na face adaxial os elementos epidérmicos apresenta forma retangular em secção transversal, com paredes anticlinais e periclinais internas espessadas. $\mathrm{O}$ espessamento acentua-se em relação às paredes periclinais externas nas células adjacentes ao bordo.

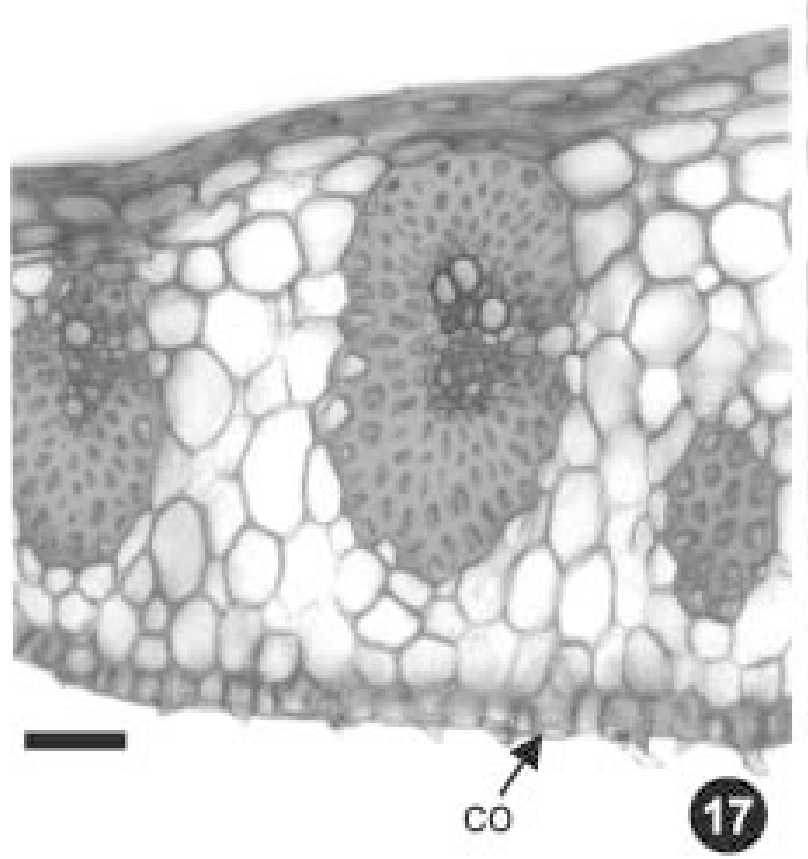

$\mathrm{Na}$ face abaxial observa-se a ocorrência de estômatos, células oleíferas e numerosos tricomas unicelulares, simples, de tamanho variado e paredes espessadas (Fig. 17).

$\mathrm{O}$ mesofilo de natureza parenquimática exibe células com paredes de espessura variável (Fig. 17). Dispersas por todo o tecido, observam-se células oleíferas (Fig. 18). O sistema vascular, imerso no parênquima, é constituído por feixes colaterais envolvidos por bainha mecânica (Fig. 17), sendo mais congestos nas proximidades do bordo onde se intercalam com cordões de fibras.

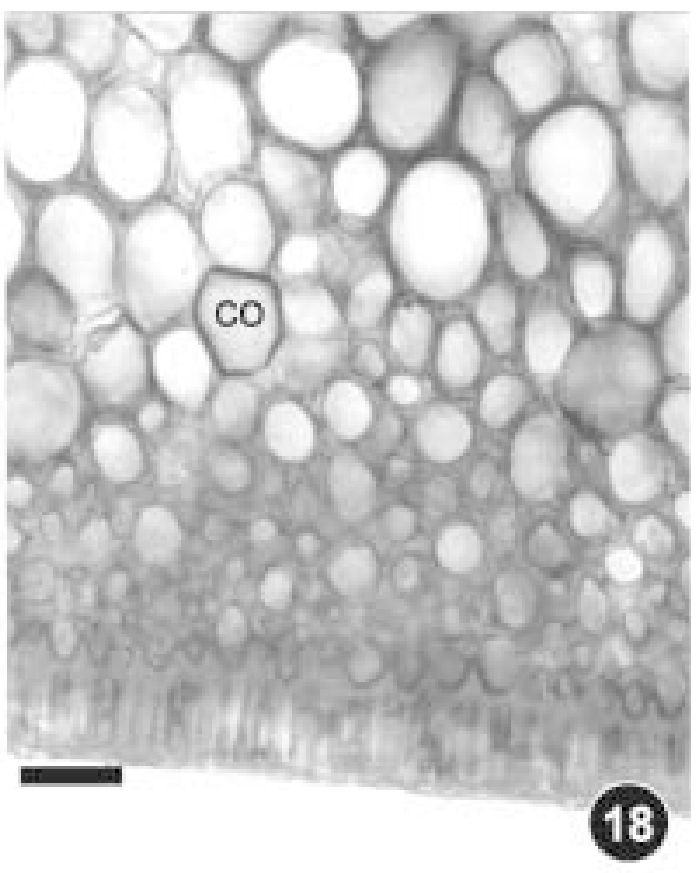

Figuras 17-18. Secções transversais da lígula. 17. Região adjacente ao bordo: cordão de fibras, célula oleífera e tricomas (barra = 58 $\mu$ m). 18 . Região proximal: célula oleífera (barra $=44 \mu \mathrm{m})$. co - célula oleífera.

\section{Discussão}

As folhas das monocotiledôneas variam em forma e estrutura podendo algumas se assemelharem às folhas das dicotiledôneas, diferenciadas em pecíolo e lâmina. No entanto, a maioria possui bainha e lâmina, sendo esta relativamente estreita (Esau 1977). Arber (1918) definiu que a folha típica das monocotiledôneas tem forma simples, mais ou menos linear, com base alargada e nervuras paralelas. A autora questiona como tal folha pode ser comparada com a das dicotiledôneas que é constituída por estípulas, pecíolo e lâmina com nervuras reticuladas.
A idéia dominante da relação estrutural entre as folhas lineares das monocotiledôneas e os apêndices foliares das dicotiledôneas tem sido a teoria do filódio proposta por De Candolle (1827 apud Kaplan 1975) e apoiada por Henslow (1911 apud Kaplan 1975), Arber (1918) e Eames \& Mac Daniels (1953). De acordo com os autores referidos, a porção achatada e fotossintética observada em Sagittaria, Hyacinthus, Flagellaria e outros gêneros, corresponde à bainha da folha ou ao pecíolo transformado, constituindo o filódio. Para Mauseth (1988), a nervura mediana também pode originar o filódio. A esse conceito puramente organográfico Arber (1918; 1925 apud Kaplan 1975) 
acrescentou evidências anatômicas relacionadas à vascularização. Uma dessas evidências foi ressaltada por Eames (1961), que relatou a venação paralela, típica das monocotiledôneas, como característica da bainha da folha e do pecíolo.

A teoria do filódio também considera que, em contraste com a redução da folha pela perda de sua lâmina, a especialização pode ocasionar o desenvolvimento de uma nova parte da folha (Kaplan 1975). Assim, uma segunda lâmina forma-se pela expansão da extremidade distal do filódio peciolar (Kaplan 1975). Além das palmeiras, das Alismataceae, dos gêneros Smilax, Eichornia e Pontederia, a ordem Scitamineae também é citada como exemplo (Eames 1961). Em tais lâminas, a venação paralela é considerada uma evidência para a natureza peciolar da lâmina, muito embora a venação dos grupos citados seja comumente intermediária entre a paralela e a reticulada (Eames 1961). Mauseth (1988) confirmou tal fato ao assinalar que a família Zingiberaceae possui folhas largas como as dicotiledôneas, mas não possui venação reticulada, observando que todas as nervuras secundárias partem da nervura principal e dirigem-se paralelamente aos bordos. Tal padrão de venação ocorre na folha de A. zerumbet e destas nervuras secundárias partem pequenas nervuras terciárias que cruzam transversalmente as secundárias. Segundo Mauseth (1988), essas nervuras são chamadas de feixes comissurais. O padrão de venação citado pelo autor como venação lateral paralela, dá um indício do crescimento da lâmina a partir da nervura mediana.

Alpinia zerumbet tem sido descrita como planta rizomatosa, apresentando folhas diferenciadas em lâmina, pecíolo curto, lígula e bainha. A maioria das lâminas das monocotiledôneas tem organização histológica homogênea do mesofilo, caráter que reforça a origem peciolar da estrutura. Alpinia zerumbet, no entanto, possui organização dorsiventral, típica das lâminas das dicotiledôneas e que pode aqui ser explicada em relação ao posicionamento das folhas, visto que se apresentam patentes, propiciando a especialização em parênquima paliçádico e lacunoso. Convém assinalar que a diferenciação do mesofilo dos exemplares que constituem a população de $A$. zerumbet no Horto Botânico do Museu Nacional independe do grau de insolação a que estão submetidos os indivíduos.

Mauseth (1988) relatou que muitas monocotiledôneas possuem pseudopecíolos, considerando-os uma terceira parte da folha, além da lâmina e da bainha. O autor cita como exemplo o gênero Alpinia, explicando que o termo é usado para definir uma estrutura que lembra um pecíolo, na forma e função, mas que teria evoluído, recentemente, de uma folha ancestral séssil.

No presente trabalho, a região posicionada entre a bainha e a lâmina é descrita como pecíolo, ignorandose a denominação dada por Mauseth (1988). No entanto, a presença de células parenquimáticas modificadas, posicionadas nas proximidades de um dos bordos, pode ser indício da evolução sugerida pelo autor.

O pecíolo é curto, caráter que se acentua pela assimetria da base da lâmina, tornando seus limites pouco precisos e, ao nível histológico, exibe as características comuns ao órgão. O tecido vascular distribui-se, preferencialmente, em cordões relacionados à face abaxial da estrutura, guarnecidos por conspícuos cordões de fibras. Por todo o parênquima fundamental encontram-se feixes vasculares de pequeno porte, com padrão de distribuição típico das monocotiledôneas, estando todos associados a fibras. A abundância e posicionamento do tecido mecânico garante a resistência necessária ao pecíolo para manter a posição da lâmina foliar, impedindo seu flexionamento. Papel idêntico atribui-se às fibras encontradas na nervura mediana da lâmina onde formam cordões calibrosos. A importância das fibras em A. zerumbet foi relatada por Tomlinson (1956), que lhes atribui valor comercial.

A presença de lígula tem sido registrada para a família Zingiberaceae e Costaceae (Judd et al. 1999). De acordo com Van Nam (1975), a ordem Zingiberales (=Scitamineae) foi pouco estudada no que concerne ao aparelho ligular. Para o autor, das famílias que compõem a ordem, somente as Marantaceae e parcialmente as Zingiberaceae foram examinadas, sendo que desta família, as observações são precárias, conduzindo a opiniões contraditórias. Barthelat (1893 apud Tomlinson 1956) considerou que a lígula das Zingiberaceae é constituída por um prolongamento das duas epidermes da bainha que, ao nível da base do limbo, fundem-se e continuam a crescer, originando uma lâmina fina, bilobada no ápice.

Segundo Cronquist (1977), a lígula é ontogeneticamente uma projeção do extremo da bainha. Muito embora não se tenha realizado, no presente trabalho, estudos relativos à origem da lígula, as evidências morfológicas e histológicas permitem considerá-la uma projeção da bainha, em concordância com Barthelat (1893 apud Tomlinson 1956), Cronquist (1977) e Van Nam (1975). Em A. zerumbet a lígula é constituída pelos estratos epidérmicos e camadas de tecido parenquimático, em meio ao qual dispõem-se feixes vasculares, fato que se acha em concordância com as observações de Chaffey (1985). Para o autor, 
as lígulas desempenham papel protetor, uma vez que, por estarem pressionadas contra o caule, evitam que água e impurezas instalem-se entre a bainha da folha e o caule.

A presença de corpúsculo silicoso nas células epidérmicas que recobrem as nervuras é característica marcante na espécie estudada, sendo este caráter apontado por Tomlinson (1969) para a tribo Alpineae. Tomlinson (1969) e Metcalfe (1954) denominaram tal arranjo como stegmata, sendo o termo, em verdade, aplicado por Netolitzky (1929) para as células que possuem um corpo silicoso ou cristal de oxalato de cálcio, dispostas em fileiras paralelas às fibras.

Solereder \& Meyer (1930 apud Tomlinson 1956) descreveram, para a família Zingiberaceae, cinco tipos de células silicosas, porém apenas as que são encontradas em Alpinia allughas são consideradas as verdadeiras stegmata devido ao espessamento das paredes celulares. Tomlinson (1956) considerou, entretanto, irrelevante o espessamento da parede para definir os verdadeiros stegmata, enquanto se ignora as características dos corpos silicosos. Para o autor, devese aplicar o termo stegmata a cada célula mais ou menos isodiamétrica, contendo um único corpo silicoso, disposta em séries longitudinais, sempre adjacentes e paralelas às fibras das bainhas dos feixes, tal como observado em A. zerumbet.

Sílica também ocorre nas células epidérmicas da nervura mediana de A. zerumbet. Essa característica acha-se em desacordo com Tomlinson (1969), que registrou, para a família Zingiberaceae, sílica em toda a epiderme, com exceção das células dos estômatos. Solereder \& Meyer (1930 apud Tomlinson 1956) devotaram considerável atenção à natureza e à distribuição de inclusões silicosas em Zingiberaceae, mas assinalaram que sua ocorrência e distribuição necessitam de maiores investigações.

$\mathrm{Na}$ espécie estudada, os estômatos são pouco freqüentes na epiderme da face adaxial da lâmina foliar, distribuindo-se, preferencialmente, na região intercostal da face abaxial, o que se acha em concordância com Tomlinson (1969). Segundo Esau (1977), o número de estômatos por unidade de superfície é tão variável que possui pouco valor taxonômico. Entretanto, tratando-se de uma monocotiledônea, a diferença de densidade expressa a disposição espacial das lâminas, eretas em muitas espécies, e patentes em outras, tal como se observa em A. zerumbet. Segundo a autora, o aspecto dos estômatos em vista frontal, especialmente com referência à natureza e orientação das células subsidiárias, serve como característica taxonômica.
Os estômatos observados na parte vegetativa foram classificados como tetracíticos, concordando com Tomlinson (1969) e Paliwal (1969), que os classificaram apenas como tetracíticos ou tetraperígenos, respectivamente, com base na presença de um par de células posicionadas na região polar das células oclusivas. Em A. zerumbet, estas células terminais estão presentes, porém podem ser em maior número em decorrência de divisões transversais desses elementos.

Metcalfe (1963) relatou que tricomas são menos comuns em monocotiledôneas do que em dicotiledôneas. Em A. zerumbet registrou-se a presença de tricomas tectores, posicionados no bordo da lâmina foliar e na face abaxial da nervura mediana, o que foi confirmado por Tomlinson (1969). Entretanto, o autor não relata a presença de tricomas na epiderme abaxial da lígula, conforme observado na espécie estudada. O mesmo autor assinalou que os tricomas são, em geral, não ramificados, exceto em Renealmia e Aframomum. Entretanto, tricomas com esta característica foram observados, ocasionalmente, no bordo da lâmina foliar de A. zerumbet. Tomlinson (1956) comentou que os tricomas são lignificados em algumas espécies de Alpinia, porém, esta característica não foi comprovada no presente trabalho. Tomlinson (1956) assinalou, no entanto, que em $A$. sanderae, tricomas lignificados ou não podem se alternar, registrando, ainda, que as paredes espessadas dos tricomas coram-se pela safranina mesmo quando o teste para a lignina com floroglucina clorídrica revela-se negativo, característica que ocorre em A. zerumbet.

Tomlinson (1956) registrou, para o gênero Alpinia, a presença de hipoderme apenas na face adaxial. Entretanto, a espécie aqui estudada apresenta não só hipoderme na face adaxial, como na abaxial, embora nesta não seja contínua e as células mostrem menores dimensões. Tomlinson (1956) explicou que, em algumas espécies de Zingiberaceae, pelo fato dos estômatos serem menos freqüentes na epiderme superior, a hipoderme adaxial forma uma camada mais ou menos ininterrupta; a hipoderme abaxial, entretanto, é interrompida pelas amplas câmaras subestomáticas.

As células hipodérmicas são grandes, aproximadamente cúbicas, sem coloração, e, ocasionalmente, contêm cristais de oxalato de cálcio, tanino e raramente, sílica (Tomlinson 1956). Em A. zerumbet não se registrou a presença de cristais ou de sílica, porém houve reação para os testes de tanino, açúcares redutores, mucilagem e alcalóides.

Para Tomlinson (1956), a hipoderme é um tecido característico da ordem Scitamineae, porém de acordo 
com Solereder \& Meyer (1930 apud Tomlinson 1956), ela é menos desenvolvida em Zingiberaceae. Estes dois autores sugeriram que a hipoderme tem a função de armazenar água, o que foi confirmado por Skutch (1930) ao estudar algumas espécies de Scitamineae, como Alpinia exaltata. $\mathrm{O}$ autor menciona que as células hipodérmicas na nervura mediana estão associadas com o desenrolar da folha, atuando como células de expansão. Tal teoria pode justificar a existência do maior número de estratos celulares na porção da lâmina de A. zerumbet nas proximidades da nervura mediana, tendo em vista a pré-foliação convoluta da folha.

A presença de canais aeríferos nos tecidos da folha de muitas monocotiledôneas é fato que levou Henslow (1892 apud Tomlinson, 1962) a sugerir que todo o grupo tivesse um ancestral aquático. Essa idéia não foi compartilhada por Tomlinson (1962), que a considerou resultante da teorização de um botânico familiarizado apenas com as monocotiledôneas de regiões temperadas, onde elas não mostram sua maior diversidade. Aerênquima nos tecidos das Scitamineae, de acordo com Tomlinson (1962), é provavelmente uma conseqüência mecânica da utilização de menor quantidade de tecido fundamental por um órgão grande que se desenvolve rapidamente.

Em A. zerumbet foi registrado aerênquima tanto no pecíolo quanto na nervura mediana da folha, posicionado entre os feixes de grande calibre relacionados à face abaxial. Tomlinson (1962) comentou que a presença de dois sistemas de aerênquima, um adaxial e outro abaxial, é característica primitiva e que tende à redução até um único arco abaxial em todas as famílias de Scitamineae, exceto Heliconiaceae e Lowiaceae, enquanto em Costaceae os canais aeríferos são reduzidos ou ausentes. Para as Zingiberaceae, o autor referiu que os canais aeríferos estão mais ou menos alternados com os feixes vasculares da face abaxial, o que foi constatado no presente trabalho.

Tomlinson (1956) relatou que compostos taníferos são muito freqüentes em todas as espécies de Zingiberaceae, sendo sua distribuição característica muito variável e, conseqüentemente, não têm valor taxonômico dentro da família. Tais compostos conferem apenas proteção à planta contra a desidratação, putrefação e lesões causadas por animais (Fahn 1985).

Em A. zerumbet foi observada grande quantidade de idioblastos taníferos concordando com Tomlinson (1969), que registrou grande concentração de tais idioblastos no tecido parenquimático fundamental de todas as partes vegetativas estudadas. $\mathrm{O}$ mesmo autor comentou que ocasionalmente, pode-se encontrar taninos no conteúdo dos tricomas do bordo da folha, o que se confirma no presente trabalho.

Cristais são freqüentemente classificados, segundo Esau (1977), como produtos de excreção mas, possivelmente, parte do cálcio é reciclada. Segundo Metcalfe (1989), há opiniões divergentes em relação ao papel desempenhado pelos cristais, pois vários significados metabólicos são atribuídos à sua freqüência, como por exemplo, proteger o vegetal contra herbivoria, dar suporte mecânico aos tecidos em época de seca e até neutralizar grande quantidade de ácido oxálico nocivo à planta.

Cristais prismáticos de oxalato de cálcio foram observados no parênquima clorofiliano da lâmina foliar e no parênquima intercalar aos feixes vasculares da nervura mediana e do pecíolo. Neste ocorrem, também, cristais no parênquima fundamental. Tal distribuição concorda com a registrada por Tomlinson (1969) e sugere função protetora e de suporte mecânico. Solereder \& Meyer (1930 apud Tomlinson 1956) sugeriram que a presença de grande quantidade de cristais de oxalato de cálcio pode ter valor taxonômico em certas espécies, porém os autores assinalaram que podem haver variações na quantidade de cristais em diferentes amostras de uma mesma espécie, como em Alpinia javanica. Segundo Tomlinson (1956), a distribuição destes cristais sugere que estejam associados com a síntese de carboidratos, já que são abundantes na lâmina foliar e estão confinados no clorênquima do pecíolo e da bainha da folha, enquanto são incomuns nas partes mais inferiores, como as raízes.

Elementos secretores considerados especializados ocorrem em algumas famílias de Scitaminae, como por exemplo, as células de mucilagem de Cannaceae, os laticíferos de Musaceae e as células oleíferas de Zingiberaceae (Tomlinson 1962).

Tomlinson (1956) registrou para as Zingiberaceae a presença de células oleíferas de forma isodiamétrica, paredes suberificadas, distribuídas no parênquima fundamental de todos os órgãos estudados e na epiderme da lâmina. Em A. zerumbet, as células oleíferas têm as mesmas características e foram encontradas em toda a folha. No entanto, a forma isodiamétrica só é reconhecida para as células oleíferas encontradas no parênquima, uma vez que as células posicionadas na epiderme têm secção poligonal.

As células oleíferas são provavelmente a fonte de muitas substâncias que tornam as espécies de Zingiberaceae comercialmente importantes como plantas aromáticas (Tomlinson 1956). As essências ou óleos essenciais, contidas em tais células, segundo Fahn 
(1979), contêm grande variedade de terpenos, sendo o grupo mais importante das substâncias secretadas.

Para a planta, além de representar reservas, os óleos essenciais desempenham outras funções (Wattiez $\&$ Sternon 1942). Seu perfume, além de atrair os polinizadores, é útil para proteger a planta contra o ataque de herbívoros. Confere-se a tais óleos a proteção dos tecidos contra o excesso de calor nas regiões onde o clima é seco, na redução da atividade de transpiração, no controle da função osmótica, provocando e acelerando o movimento da água através da parede celular e, por conseqüência, o transporte de enzimas e materiais solúveis (Wattiez \& Sternon 1942).

Metcalfe (1963) ressaltou que a anatomia pode ser utilizada para solucionar diversos problemas taxonômicos, principalmente no que se refere ao grupo das monocotiledôneas. Relatou ainda que a ocorrência e/ou a distribuição de corpúsculos silicosos, de células oleíferas, de hipoderme, de aerênquima e de estômatos, características estas estudadas no presente trabalho, possuem grande valor taxonômico dentro no grupo.

A folha de Alpinia zerumbet possui muitas características comuns mencionadas por Tomlinson (1956; 1962; 1969) e Metcalfe (1963) para a família Zingiberaceae. Como as monocotiledôneas são relativamente pouco estudadas, conclui-se que o reconhecimento dos caracteres anatômicos aqui analisados torna-se relevante para o conhecimento da morfologia da espécie de $A$. zerumbet, bem como da taxonomia da família.

\section{Referências bibliográficas}

Almeida, E. R. 1993. Plantas medicinais brasileiras conhecimentos populares e científicos. Hemus Editora, São Paulo.

Arber, A. 1918. The phyllode theory of the monocotyledonous leaf, with special reference to anatomical evidence. Annals of Botany 32: 465-501.

Beille, L. 1925. Précis de Botanique Pharmaceutique. Maloine et Fils, Paris.

Carlini, E. A. 1972. "Screening" farmacológico de plantas brasileiras. Revista Brasileira de Biologia 32(2): 265274.

Chaffey, N. J. 1985. Structure and function in the grass ligule: optical and electron microscopy of the membranous ligule of Lolium temulentum L. Annals of Botany 55: 65-75.

Costa, A. F. 1982. Farmacognosia. Fundação Calouste Gulbenkian, Lisboa.

Cronquist, A. 1977. Introduccion a la Botanica. 2 ed. Ed. Continental, México.
Cronquist, A. 1981. An integrated system of classification of flowering plants. Columbia University Press, New York.

Dahlgren, R. M. T.; Clifford, H. T. \& Yeo, P. F. 1985. The families of the Monocotyledons - Structure, evolution, and taxonomy. Springer-Verlag, Berlim.

De Pooter, H. L.; Aboutabl, E. A. \& EL-Shabrawy, A. O. 1995. Chemical composition and antimicrobial activity of essential oil of leaf, stem and rhizome of Alpinia speciosa (J. C. Wendl.) K. Schum, grown in Egypt. Flavour Fragrance Journal 10(2): 63-67.

Dop, P. \& Gautié, A. 1928. Manuel de technique botanique. 2 ed. J. Lamarre, Paris.

Eames, A. J. 1961. Morphology of the Angiosperms. Tata McGraw-Hill Publishing Co., India.

Eames, A. J. \& Mac Daniels, L. H. 1953. An introduction to plant anatomy. 2 ed. McGraw-Hill Book Company, New York.

Esau, K. 1977. Anatomy of seed plants. 2 ed. John Wileys and Sons, New York.

Fahn, A. 1979. Secretory tissues in plants. Academic Press, London.

Fahn, A. 1985. Anatomia Vegetal. Ediciones Pirámide, Madrid.

Fujita, H \& Yamashita, M. 1973. The constituents of the essential oil from Alpinia speciosa K. Schum. Yakugakuzasshi 93(12): 1635-1638.

Goldberg, A. 1989. Classification, evolution, and phylogeny of the families of Monocotyledons. Smithsonian Contributions to Botany 71: 1-74.

Howarth, W. \& Warne, L. G. G. 1959. Practical botany for the tropics. University of London Press, London.

Hussin, K. H.; Seng, C. T.; Ibrahim, H.; Gen, W. Q.; Ping, L. J. \& Nian, L. 2000. Comparative leaf anatomy of Alpinia Roxb. species (Zingiberaceae) from China. Botanical Journal of the Linnean Society 133(2): 161-180.

Janssen, A. M. \& Scheffer, J. J. C. 1985. Acetoxychavicol acetate, an antifungal component of Alpinia galanga. Planta Medica 6: 507-510.

Jensen, W. A. 1962. Botanical histochemistry. H. H. Friman \& Co., San Francisco.

Johansen, D. A. 1940. Plant Microtechnique. Mc Graw Hill Book, New York.

Joly, A. B. 1993. Botânica - Introdução à taxonomia vegetal. Companhia Editora Nacional, São Paulo.

Judd, W. S.; Campbell C. S.; Kellog, E. A. \& Stevens, P. F. 1999. Plant systematics - a phylogenetic approach. Sinauer Associates, Sunderland, Massachussets,

Kaplan, D. R. 1975. Comparative developmental evaluation of the morphology of unifacial leaves in the monocotyledons. Botanische Jahrbücher für Systematik, Pflanzengeschichte und Pflanzengeografrie 95(1): 1-105.

Kishore, N.; Asthana, A. \& Dubey, N. K. 1987. Antifungal activity of rhizome vapours of Alpinia carinata against Rhizoctonia solani. Transactions of the British Mycological Society 88(1): 136-138.

Kress, W. J.; Prince, L. M. \& Williams, K. J. 2002. The phylogeny and a new classification of the gingers (Zingiberaceae): evidence from molecular data. American Journal of Botany 89(10): 1682-1696. 
Langeron, M. 1949. Précis de Microscopie. Masson et Editeurs, Paris.

Laranja, S. M. R.; Bergamaschi, C. M. \& Schor, N. 1992. Avaliação de três plantas com potencial efeito diurético. Revista Associação Médica Brasileira 38(1): 13-16.

Lima, E. O.; Gompertz, O. F.; Giesbrecht, A. M. \& Paulo, M. Q. 1993. In vitro antifungal activity of essential oils obtained from officinal plants against dermatophytes. Mycoses 36: 333-336.

Lorenzi, H. \& Souza, H. M. 1995. Plantas ornamentais no Brasil - arbustivas, herbáceas e trepadeiras. Editora Plantarum, São Paulo.

Machado, L. D. 1996. Alpínia. Revista Natureza 101(5): 39-42.

Mauseth, J. D. 1988. Plant Anatomy. The Benjamin/Cummings Publishing Company, California.

Mc Lean, R. C. \& Ivimey-Cook, W. R. 1958. Plant science formulae. Mc Millan \& Co., London.

Mendonça, V. L. M.; Oliveira, C. L. A.; Craveiro, A. A.; Rao, V. S. \& Fonteles, M. C. 1. 1991. Pharmacological and toxicological evaluation of Alpinia speciosa. Memórias do Instituto Oswaldo Cruz 86(Suppl. II): 93-97.

Metcalfe, C. R. 1954. Recent work on the systematic anatomy of the monocotyledons - with special references to investigations at the Jodrell Laboratory at Kew. Kew Bulletin 523-532.

Metcalfe, C. R. 1963. Comparative anatomy as a modern botanical discipline - with special reference to recent advances in the systematic anatomy of monocotyledons. Advances in Botanical Research 1: 101-147.

Metcalfe, C. R. \& Chalk, L. 1950. Anatomy of the Dicotiledons. Clarendon Press, Oxford.

Metcalfe, C. R. 1989. Secreted mineral substances. In: C.R. Metcalfe \& L. Chalk. Anatomy of the Dicotiledons. Clarendon Press, Oxford, v.2.

Morita, D. 1992. Insecticides and bactericide made of sell flower essential oil. Int. Cl A $01 \mathrm{~N}$ 25/00. US Patent 5110594.
Netolitzky, F. 1929. Die Kieselkörper. Pp. 1-19. In: Linsbauer. K. Handbuch der Pflanzenanatomie. Gebrüder Borntraeger, Berlim.

Paliwal, G. S. 1969. Stomatal ontogeny and phylogeny. I. Monocotyledons. Acta Botanica Neerlandica 18(5): 654-668.

Rao, B. G. V. N. \& Nigam, S. S. 1970. The in vitro antimicrobial efficiency of essential oils. Indian Journal of Medical Research 58(5): 627-633.

Reeve, R. M. 1951. Histochemical tests for polyphenols in plant tissues. Stain Technology 26(2): 91-96.

Santana, C. F.; Pinto, K. V. \& D’Albuquerque, I. L. 1966. Estudos farmacológicos de antiinflamatórios de alguns vegetais. Revista do Instituto de Antibióticos 6(1/2): 75-89.

Sass, J. E. 1951. Botanical microtechnique. Iowa Press Building, Iowa.

Skutch, A. F. 1930. Unrolling of leaves of Musa sapientum and some related plants and their relation to environmental acidity. Botanical Gazette 90: 337-365.

Strasburger, E. 1924. Handbook of practical botany. George Allen e Nonviirn, Ltd., 8 ed., Iowa.

Tomlinson, P. B. 1956. Studies in the systematic anatomy of the Zingiberaceae. Journal of the Linnean Society 55 : 547-592.

Tomlinson, P. B. 1962. Phylogeny of the Scitamineae Morphological and anatomical considerations. Evolution 16: 192-213.

Tomlinson, P. B. 1969. Commelinales - Zingiberales. Pp. 341-359. In: C. R. Metcalfe. Anatomy of the monocotyledons. Clarendon Press, Oxford.

Van Nam, T. 1975. Costaceae et Zingiberaceae: Leurs appareils ligulaires. Adansonia 14(4): 561-570.

Vogel, A. I. 1981. Química analítica qualitativa. Editora Mestre Jou, São Paulo.

Wattiez, N. \& Sternon, F. 1942. Élements de chimie végétale. Masson et Cie, 2 ed., Paris.

Winters, G. 1995. Jardinagem - Zingiberáceas. Revista Natureza 91(7): 14-23. 